\title{
Ofloxacin-containing combined drug regimens in the treatment of lepromatous leprosy
}

\author{
P. S. RAO, A. RAMACHANDRAN, B. SEKAR, \\ S. RAVI \& M. SUBRAMANIAN \\ Central Leprosy Teaching and Research Institute, Chengalpattu- \\ 603001, Tamil Nadu, India
}

\section{Accepted for publication 14 February 1994}

\begin{abstract}
Summary A total of 26 clinically diagnosed adult patients, with active untreated lepromatous leprosy, with a Bacteriological Index of $4+$ or more, were admitted to the hospital of the Central Leprosy Teaching and Research Institute, Chengalpattu, India, between 1989 and 1991. After prescribed investigations, the patients were randomly allocated in groups of 3 to 3 treatment regimens, namely: 1 , clofazimine $50 \mathrm{mg}$ daily and $300 \mathrm{mg}$ once in 4 weeks + dapsone $100 \mathrm{mg}$ daily (AA); 2, (AA)+ofloxacin $400 \mathrm{mg}$ daily (BB); and 3, (AA)+ofloxacin $800 \mathrm{mg}$ daily (CC). The drugs were administered for 56 days continuously under supervision. Sequential biopsy results on day $0,7,14,28$ and 56 in normal mouse footpad revealed no growth by day 28 and 56 in all patients treated with CC and BB regimens, respectively. Calculation of the proportion of viable Mycobacterium leprae through analysis of median infectious dose $\left(\mathrm{ID}_{50}\right)$ showed significant differences on day 7 in the percentage of kill between the ofloxacin-containing regimens and the other. Moderate to marked clinical improvement has been observed in a significantly higher proportion of patients treated with ofloxacin-containing regimens. All the 3 regimens were well tolerated. No severe complications or side-effects to the drugs were noticed with any of the regimens that required any suspension of treatment or the administration of steroids. Addition of ofloxacin to the standard WHO recommended MDT regimen for multibacillary patients may reduce the present duration of therapy. Ofloxacin may also be considered as an alternative drug in rifampicin-resistant cases or where rif ampicin is contraindicated.
\end{abstract}

\section{Introduction}

The identification of bactericidal chemotherapeutic agents and the determination of their appropriate dosages and duration with and without other drugs is a priority in the quest for leprosy control, in the absence of a primary preventive measure such as an effective vaccine. There are only 4 bactericidal drugs (rifampicin, dapsone, clofazimine and thiomides) which are recommended for combined drug regimens, ${ }^{1}$ and are widely used in the treatment of lepromatous leprosy. Each of the last 3 drugs, besides being weakly 
bactericidal, suffer from various drawbacks, such as an increased emergence of resistant $M$. leprae to dapsone, ${ }^{2}$ skin discolouration with the use of clofazimine, ${ }^{3-5}$ and the hepatotoxicity of thiomides. ${ }^{6,7}$ Even resistance to rifampicin, has been reported. ${ }^{8,9}$ Hence there is an urgent need to search for newer more potent bactericidal drugs, the detection of which might also help in reducing the duration of treatment. Several fluoroquinolones, especially ofloxacin, were found to be most active against M. leprae in vitro ${ }^{10}$ and in vivo. ${ }^{11}$

Limited clinical trials concluded with ofloxacin and pefloxacin alone or in combination with other drugs reported highly favourable results in terms of tolerance, sideeffects, clinical improvement and reduction in viable $M$. leprae. ${ }^{12,13} \mathrm{~A}$ randomized clinical trial in lepromatous leprosy patients administered regimens containing dapsone, clofazimine and ofloxacin, has been conducted to find out the rate of kill of M. leprae in the mouse footpad model, the clinical response and the side-effects to drugs, and the results are reported below.

\section{Materials and methods}

A total of 26 clinically diagnosed, adult patients with active, untreated lepromatous leprosy were admitted to the hospital of the Central Leprosy Teaching and Research Institute, Chengalpattu, India, between September 1989 and December 1991. As well as close questioning on their first examination, a urine spot test for dapsone was conducted and we estimated their creatinine-dapsone ratio, to establish each patient's treatment status at intake. The procedures laid down in the standard THELEP protocol for examination, investigation and documentation of lepromatous leprosy patients were followed. After a thorough examination, patients received slit-skin smears for the bacteriological index (BI) and the morphological index (MI), and routine blood, urine and stool examinations, a skiagram of the chest, a lepromin test, and liver and kidney function tests were carried out. Biopsies were collected from sites with BI $\geqslant 4+$ for mouse footpad (MFP) inoculation and histopathology. Patients with either a history of ENL reactions or who had complications with other diseases such as diabetes and tuberculosis, or were over 65 years, or pregnant women were excluded from the study. Patients were allocated randomly in groups of $3^{14}$ to the 3 regimens, namely: 1, clofazimine $300 \mathrm{mg}$ once in 4 weeks and $50 \mathrm{mg}$ daily + dapsone $100 \mathrm{mg}$ daily for 56 days (AA regimen); 2, AA regimen $+400 \mathrm{mg}$ of ofloxacin daily for 56 days (BB regimen); and 3, AA regimen $+800 \mathrm{mg}$ of ofloxacin daily for 56 days (CC regimen). Biopsies were collected from each of the patients on day $0,7,14,28$ and 56 of treatment from the same site. After processing, biopsy suspensions were inoculated into both hind footpads of each mouse in dilutions of $10^{4}, 10^{3}, 10^{2}$ and $10^{1}$ using 10 normal albino mice aged 6-8 weeks for each dilution, duly following Shepard's technique. Harvesting of footpads was done 1 year after inoculation. Smear BI and MI examination was repeated on day 28 and 56. Liver and kidney function tests and other haematological examinations were repeated at each biopsy. Prescribed drugs were administered daily under supervision and clinical progress was documented. The presence of $\geqslant 10^{5}$ organisms per footpad on harvesting was taken as positive for growth in MFP. The calculation for arriving at the proportion of viable organisms through the analysis of median infectious doses $\left(\mathrm{ID}_{50}\right)$ and significance were made as described in Laboratory techniques in leprosy published by 
WHO. ${ }^{15}$ If no growth had been detected after the commencement of the chemotherapy, it was assumed that growth had occurred in a footpad inoculated with the maximum concentration of inoculum for arriving at the probable proportion of the viable organism. The difference in proportion of the viable organism distribution in different regimens on day 0 , median percentage of kill on day 7 between regimens and the frequency of significant reduction at day 7 were tested by Mann-Whitney and Fisher's exact tests for significance. Comparisons were not made for frequency of significant reduction beyond day 7. Clinical improvement was judged by flattening of the nodules, regression of infiltration, clearance of erythema and improvement in nasal congestion, etc. All the cases were put on the WHO recommended multidrug treatment regimen for MB patients on completion of the 56 days of trial. The study was not blind.

\section{Results}

PROPORTION OF VIABLE ORGANISMS, GROWTH IN MFP AND PERCENTAGE OF KILL

Of the 26 cases taken into the study, 3 cases (case nos 5, 11 and 12) were females and 3 were BL histopathologically (case nos 2, 5 and 15). Case no. 22 dropped out from trial after day 28. The number of MFP harvested and found positive for growth is given in Table 1 . No growth was detected from day 0 of biopsy inoculation in 7 cases (case nos 1 , $4,5,11,12,14$ and 18) and hence they were excluded from analysis. The growth in MFP has been found to be negative in all patients treated with CC regimen by day 28 and with $\mathrm{BB}$ regimen by day 56 (Figure 1), whereas the growth was found positive in 1 patient on day 56 with AA regimen. However, 1 case under BB regimen showed growth in 1 MFP among 40 harvested at day 14 and 1 of 64 harvested at day 28, after attaining negativity at day 7 during the course of treatment (case no. 8).

The proportion of viable organisms, in general, was found to be very low on day 0 , though inoculations were made from biopsy suspensions from sites showing BI $\geqslant 4+$. There were wide variations in the proportion of viable organisms in all the regimens. Despite randomization of patients in groups of 3 , there were significant differences between the medians of proportion of viable organisms among the regimens at day 0 , being highest in AA regimen (Table 2). It is observed that the lower the proportion of viable organisms on day 0 , the less was the percentage of organisms killed by day 7 with any of the regimens. The maximum kill has occurred between day 0 and 7 in BB and $C C$ regimens. The median percentage of kill has been found to be significantly higher in $\mathrm{BB}$ and $\mathrm{CC}$ regimens when compared to AA regimen (Table 2). The frequency of significant reduction of proportion of viable organisms on day 7 apparently appears to be more in $\mathrm{BB}$ and $\mathrm{CC}$ regimens compared to AA. The precise estimation of percentage of kill beyond day 7 could not be made in $\mathrm{BB}$ and $\mathrm{CC}$ regimens because no growth occurred in the footpad in most of the cases, which is perhaps due to very low proportion of viable organisms at day 0 . MI and BI on day 0,28 and 56 is shown in Table 3. In general MI at intake of cases was found to be low and even 0 in 9 cases. There has been consistent fall in MI in all the cases with progress of treatment. In 11 out of 17 cases $(64 \cdot 7 \%)$ the MI has reached $0.0 \%$ by day 56 . No significant differences were noticed in the fall of MI between the regimens.

CLINICAL IMPROVEMENT BY DAY 56

Clinical assessment has been graded as 'nil', 'mild', 'moderate' and 'marked improve- 
Table 1. Results of mouse footpad inoculation with organisms recovered from biopsy taken before and during treatment

\begin{tabular}{|c|c|c|c|c|c|c|c|c|c|c|c|c|c|c|c|c|c|c|c|c|c|}
\hline \multirow{2}{*}{$\begin{array}{l}\text { Case } \\
\text { no. }\end{array}$} & \multirow[b]{2}{*}{ Regimen } & \multicolumn{4}{|c|}{0 day } & \multicolumn{4}{|c|}{7 th day } & \multicolumn{4}{|c|}{ 14th day } & \multicolumn{4}{|c|}{28 th day } & \multicolumn{4}{|c|}{ 56th day } \\
\hline & & $10^{4}$ & $10^{3}$ & $10^{2}$ & 10 & $10^{4}$ & $10^{3}$ & $10^{2}$ & 10 & $10^{4}$ & $10^{3}$ & $10^{2}$ & 10 & $10^{4}$ & $10^{3}$ & $10^{2}$ & 10 & $10^{4}$ & $10^{3}$ & $10^{2}$ & 10 \\
\hline 2 & $\mathrm{CC}$ & $17 / 18$ & $7 / 18$ & $1 / 18$ & $0 / 18$ & $0 / 8$ & $0 / 6$ & $0 / 2$ & $0 / 4$ & $0 / 20$ & $0 / 14$ & $0 / 18$ & $0 / 14$ & $0 / 14$ & $0 / 14$ & $0 / 18$ & $0 / 18$ & $0 / 20$ & $0 / 14$ & $0 / 20$ & $0 / 20$ \\
\hline 3 & BB & $9 / 18$ & $5 / 18$ & $0 / 14$ & $1 / 16$ & $0 / 14$ & $0 / 14$ & $0 / 18$ & $0 / 20$ & $0 / 18$ & $0 / 16$ & $0 / 16$ & $0 / 8$ & $0 / 12$ & $0 / 10$ & $0 / 8$ & $0 / 18$ & $0 / 18$ & $0 / 18$ & $0 / 12$ & $0 / 10$ \\
\hline 5 & $\mathrm{AA}$ & $0 / 10$ & $0 / 18$ & $0 / 8$ & $0 / 16$ & $0 / 18$ & $0 / 14$ & $1 / 18$ & $0 / 18$ & $0 / 10$ & $0 / 16$ & $0 / 16$ & $0 / 10$ & $0 / 20$ & $1 / 20$ & $0 / 10$ & $0 / 20$ & $0 / 14$ & $0 / 18$ & $0 / 18$ & $0 / 18$ \\
\hline 6 & $\mathrm{CC}$ & $2 / 16$ & $0 / 14$ & $1 / 14$ & $0 / 20$ & $0 / 12$ & $1 / 4$ & $0 / 16$ & $0 / 14$ & $1 / 10$ & $0 / 8$ & $0 / 10$ & $1 / 6$ & $0 / 18$ & $0 / 16$ & $0 / 18$ & $0 / 18$ & $0 / 0$ & $0 / 12$ & $0 / 0$ & $0 / 0$ \\
\hline 7 & AA & $3 / 4$ & $3 / 10$ & $0 / 8$ & $0 / 0$ & $1 / 12$ & $1 / 18$ & $0 / 16$ & $0 / 16$ & $0 / 18$ & $0 / 18$ & $0 / 12$ & $0 / 20$ & $0 / 14$ & $0 / 10$ & $0 / 14$ & $0 / 12$ & $0 / 10$ & $0 / 18$ & $0 / 2$ & $0 / 14$ \\
\hline 8 & BB & $1 / 14$ & $1 / 20$ & $0 / 16$ & $2 / 20$ & $0 / 16$ & $0 / 18$ & $0 / 18$ & $0 / 18$ & $0 / 12$ & $1 / 16$ & $0 / 6$ & $0 / 6$ & $0 / 18$ & $1 / 14$ & $0 / 14$ & $0 / 18$ & $0 / 18$ & $0 / 18$ & $0 / 18$ & $0 / 18$ \\
\hline 9 & $\mathrm{CC}$ & $2 / 14$ & $1 / 16$ & $0 / 18$ & $1 / 18$ & $1 / 18$ & $0 / 14$ & $0 / 8$ & $0 / 18$ & $0 / 14$ & $0 / 12$ & $0 / 18$ & $0 / 16$ & $0 / 16$ & $0 / 14$ & $0 / 18$ & $0 / 14$ & $0 / 14$ & $0 / 16$ & $0 / 16$ & $0 / 14$ \\
\hline 10 & $\mathrm{AA}$ & $7 / 18$ & $0 / 12$ & $0 / 18$ & $0 / 16$ & $3 / 16$ & $2 / 18$ & $0 / 14$ & $0 / 18$ & $7 / 18$ & $0 / 20$ & $0 / 18$ & $0 / 8$ & $2 / 20$ & $0 / 14$ & $0 / 8$ & $0 / 14$ & $0 / 16$ & $0 / 18$ & $0 / 18$ & $0 / 8$ \\
\hline 13 & AA & $3 / 16$ & $1 / 14$ & $0 / 16$ & $0 / 18$ & $2 / 16$ & $1 / 20$ & $0 / 18$ & $0 / 18$ & $0 / 18$ & $0 / 10$ & $0 / 12$ & $0 / 18$ & $0 / 16$ & $0 / 18$ & $0 / 10$ & $0 / 16$ & $0 / 14$ & $0 / 16$ & $0 / 10$ & $0 / 20$ \\
\hline 15 & $\mathrm{CC}$ & $2 / 16$ & $0 / 14$ & $0 / 18$ & $0 / 8$ & $0 / 20$ & $0 / 16$ & $0 / 18$ & $0 / 16$ & $0 / 18$ & $0 / 20$ & $0 / 18$ & $0 / 20$ & $0 / 16$ & $0 / 18$ & $0 / 18$ & $0 / 18$ & $0 / 18$ & $0 / 18$ & $0 / 20$ & $0 / 18$ \\
\hline 16 & AA & $4 / 16$ & $9 / 16$ & $0 / 8$ & $0 / 16$ & $4 / 20$ & $10 / 18$ & $2 / 16$ & $0 / 18$ & $6 / 20$ & $3 / 18$ & $5 / 20$ & $0 / 18$ & $4 / 14$ & $4 / 14$ & $0 / 12$ & $0 / 18$ & $0 / 16$ & $0 / 18$ & $0 / 16$ & $0 / 14$ \\
\hline 17 & BB & $4 / 16$ & $7 / 16$ & $1 / 14$ & $0 / 12$ & $0 / 16$ & $0 / 16$ & $0 / 8$ & $0 / 16$ & $0 / 16$ & $0 / 16$ & $0 / 16$ & $0 / 14$ & $0 / 14$ & $0 / 14$ & $0 / 18$ & $0 / 12$ & $0 / 16$ & $0 / 20$ & $0 / 18$ & $0 / 14$ \\
\hline 19 & $\mathrm{AA}$ & $5 / 12$ & $10 / 14$ & $2 / 20$ & $11 / 16$ & $12 / 18$ & $8 / 20$ & $0 / 16$ & $0 / 12$ & $8 / 12$ & $1 / 14$ & $0 / 10$ & $0 / 10$ & $0 / 12$ & $0 / 14$ & $0 / 8$ & $0 / 12$ & $0 / 20$ & $0 / 18$ & $0 / 18$ & $0 / 18$ \\
\hline 20 & BB & $5 / 16$ & $3 / 18$ & $2 / 20$ & $1 / 16$ & $0 / 12$ & $0 / 14$ & $0 / 12$ & $0 / 8$ & $0 / 12$ & $0 / 12$ & $0 / 14$ & $0 / 10$ & $0 / 14$ & $0 / 12$ & $0 / 14$ & $0 / 12$ & $0 / 14$ & $0 / 16$ & $0 / 18$ & $0 / 10$ \\
\hline 21 & $\mathrm{CC}$ & $11 / 16$ & $11 / 16$ & $0 / 16$ & $0 / 20$ & $6 / 14$ & $1 / 20$ & $1 / 20$ & $0 / 12$ & $0 / 12$ & $0 / 16$ & $0 / 18$ & $0 / 20$ & $0 / 20$ & $0 / 20$ & $0 / 14$ & $0 / 16$ & $0 / 18$ & $0 / 20$ & $0 / 20$ & $0 / 16$ \\
\hline 22 & $\mathrm{CC}$ & $7 / 16$ & $3 / 18$ & $0 / 20$ & $0 / 18$ & $0 / 18$ & $0 / 18$ & $0 / 16$ & $0 / 14$ & $0 / 18$ & $0 / 16$ & $0 / 16$ & $0 / 20$ & $0 / 20$ & $0 / 18$ & $0 / 18$ & $0 / 18$ & & & & \\
\hline 23 & $\mathrm{AA}$ & $8 / 20$ & $2 / 20$ & $0 / 18$ & $0 / 20$ & $2 / 18$ & $1 / 18$ & $0 / 20$ & $0 / 18$ & $0 / 20$ & $0 / 18$ & $0 / 16$ & $0 / 14$ & $0 / 12$ & $0 / 18$ & $0 / 20$ & $0 / 14$ & $0 / 20$ & $0 / 12$ & $0 / 20$ & $0 / 18$ \\
\hline 24 & BB & $1 / 16$ & $1 / 20$ & $0 / 20$ & $0 / 12$ & $0 / 18$ & $0 / 10$ & $0 / 20$ & $0 / 14$ & $0 / 18$ & $0 / 18$ & $0 / 14$ & $0 / 18$ & $0 / 12$ & $0 / 20$ & $0 / 12$ & $0 / 16$ & $0 / 20$ & $0 / 20$ & $0 / 20$ & $0 / 18$ \\
\hline 25 & BB & $14 / 18$ & $0 / 20$ & $0 / 20$ & $0 / 18$ & $4 / 20$ & $2 / 18$ & $0 / 10$ & $0 / 16$ & $0 / 18$ & $0 / 16$ & $0 / 20$ & $0 / 18$ & $0 / 18$ & $0 / 14$ & $0 / 10$ & $0 / 18$ & $0 / 20$ & $0 / 20$ & $0 / 14$ & $0 / 18$ \\
\hline 26 & AA & $16 / 16$ & $5 / 18$ & $0 / 18$ & $0 / 20$ & $12 / 18$ & $7 / 18$ & $2 / 14$ & $0 / 18$ & $10 / 20$ & $4 / 16$ & $1 / 16$ & $0 / 18$ & $6 / 12$ & $0 / 18$ & $0 / 14$ & $0 / 18$ & $13 / 20$ & $2 / 18$ & $0 / 16$ & $0 / 16$ \\
\hline
\end{tabular}

Case nos $1,4,11,12,14$ and 18 were excluded since there was no growth at all periods. 


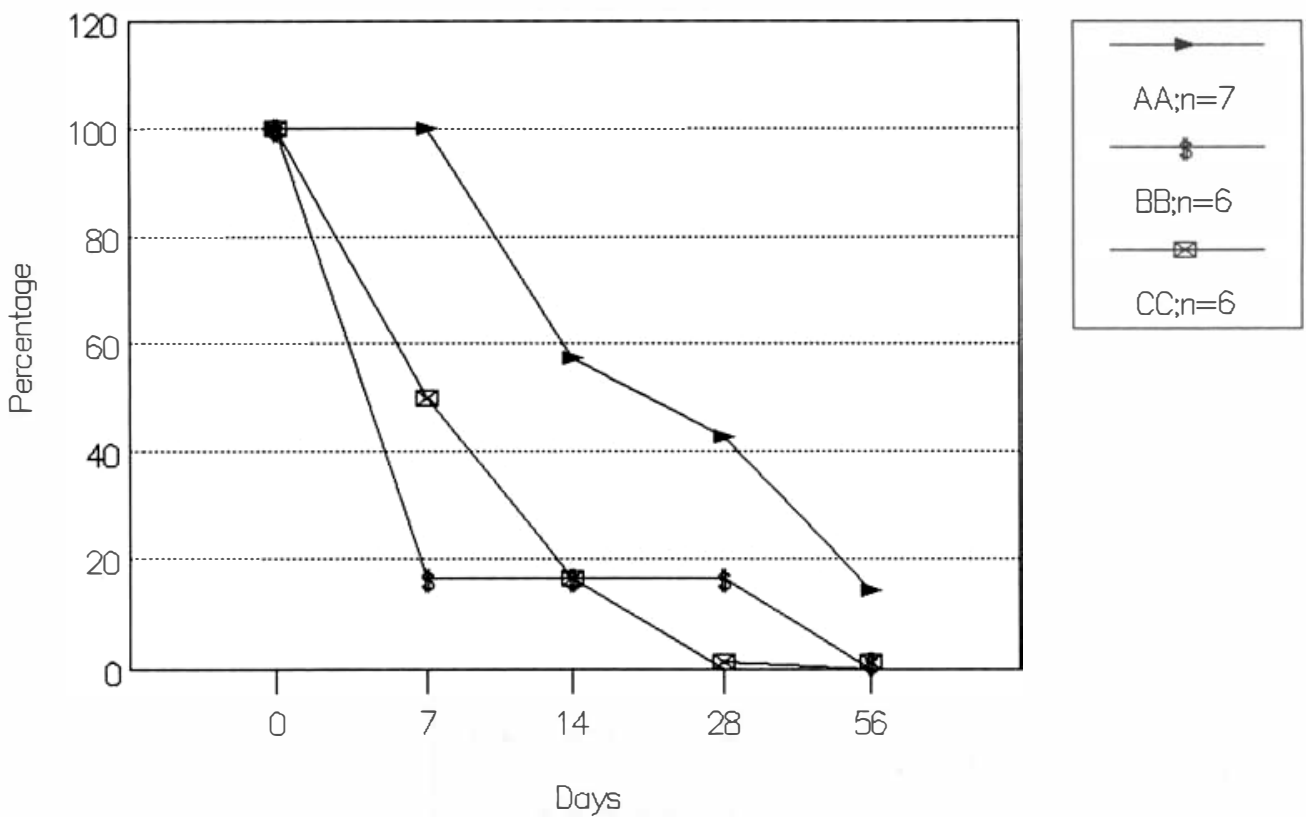

Figure 1. Cases showing growth in mouse footpad in relation to regimen.

ment'. None of these cases showed deterioration. All cases in the ofloxacin regimens (BB and $\mathrm{CC}$ ), except 1 case in CC regimen, showed improvement (11 out of 12 ), a majority of them being moderate to marked $(88 \%)$, whereas the majority in AA regimen showed no improvement at all (6 out of 9). The difference between AA and the other 2 regimens was found to be significant. All cases taken into the trial were analysed except case no. 22 .

Table 2. Distribution of proportion of viable organisms on ' 0 ' day of different regimens and their percentage of kill at different period of trial by range and median

\begin{tabular}{|c|c|c|c|c|c|c|c|c|c|c|}
\hline \multirow[b]{3}{*}{ Regimen } & \multicolumn{10}{|c|}{ Day } \\
\hline & \multicolumn{2}{|c|}{0} & \multicolumn{2}{|c|}{7} & \multicolumn{2}{|c|}{14} & \multicolumn{2}{|c|}{28} & \multicolumn{2}{|c|}{56} \\
\hline & Range & Median & Range & Median & Range & Median & Range & Median & Range & Median \\
\hline AA & $\left\{\begin{array}{c}0 \cdot 004 \\
\text { to } \\
0 \cdot 1443\end{array}\right\}$ & 0.0144 & $\left\{\begin{array}{c}-18 \cdot 91 \\
\text { to } \\
88 \cdot 0\end{array}\right\}$ & $25 \cdot 0$ & $\left\{\begin{array}{c}0 \cdot 0 \\
\text { to } \\
91 \cdot 68\end{array}\right\}$ & $63 \cdot 8$ & $\left\{\begin{array}{c}20 \cdot 8 \\
\text { to } \\
98 \cdot 26\end{array}\right\}$ & $63 \cdot 0$ & $\left\{\begin{array}{c}37 \cdot 5 \\
\text { to } \\
98 \cdot 26\end{array}\right\}$ & $70 \cdot 9$ \\
\hline BB & $\left\{\begin{array}{c}0.0029 \\
\text { to } \\
0.048\end{array}\right\}$ & 0.0105 & $\left\{\begin{array}{c}>13.91 \\
\text { to } \\
>94.8\end{array}\right\}$ & $>67 \cdot 8$ & $\left\{\begin{array}{c}>13 \cdot 8 \\
\text { to } \\
>94 \cdot 88\end{array}\right\}$ & $>75 \cdot 3$ & $\left\{\begin{array}{c}>13 \cdot 8 \\
\text { to } \\
>94.8\end{array}\right\}$ & $>75 \cdot 3$ & $\left\{\begin{array}{c}>13 \cdot 8 \\
\text { to } \\
>94 \cdot 8\end{array}\right\}$ & $>75 \cdot 3$ \\
\hline $\mathrm{CC}$ & $\left\{\begin{array}{c}0.0029 \\
\text { to } \\
0.0536\end{array}\right\}$ & $0 \cdot 0070$ & $\left\{\begin{array}{c}-12 \cdot 7 \\
\text { to } \\
>95 \cdot 3\end{array}\right\}$ & $61 \cdot 4$ & $\left\{\begin{array}{c}-18 \cdot 5 \\
\text { to } \\
>95 \cdot 3\end{array}\right\}$ & $>61 \cdot 4$ & $\left\{\begin{array}{c}>14 \cdot 9 \\
\text { to } \\
>95 \cdot 36\end{array}\right\}$ & $>61 \cdot 4$ & $\left\{\begin{array}{c}>14 \cdot 9 \\
\text { to } \\
>95 \cdot 3\end{array}\right\}$ & $>50.9$ \\
\hline
\end{tabular}


Table 3. Average BI and MI Results on day 0,28 and 56 by regimen

\begin{tabular}{|c|c|c|c|c|c|c|c|c|c|c|c|c|c|c|c|c|c|c|c|c|}
\hline \multirow{3}{*}{$\begin{array}{l}\text { Case } \\
\text { no. }\end{array}$} & \multicolumn{20}{|c|}{ Regimen } \\
\hline & \multicolumn{6}{|c|}{$\mathrm{AA}$} & \multirow{2}{*}{$\begin{array}{c}\text { Case } \\
\text { no. }\end{array}$} & \multicolumn{6}{|c|}{ BB } & \multirow{2}{*}{$\begin{array}{c}\text { Case } \\
\text { no. }\end{array}$} & \multicolumn{6}{|c|}{$\mathrm{CC}$} \\
\hline & MI & $\mathrm{BI}$ & MI & $\mathrm{BI}$ & MI & $\mathrm{BI}$ & & MI & BI & MI & BI & MI & BI & & MI & $\mathrm{BI}$ & MI & BI & MI & BI \\
\hline 1 & $1 \cdot 25$ & $4 \cdot 16$ & ND & ND & $0 \cdot 35$ & 3.67 & 3 & $2 \cdot 16$ & 5.00 & $1 \cdot 16$ & $5 \cdot 50$ & $0 \cdot 83$ & $5 \cdot 00$ & 2 & 1.5 & $5 \cdot 50$ & $1 \cdot 0$ & $4 \cdot 16$ & $1 \cdot 0$ & $4 \cdot 35$ \\
\hline 5 & 1.67 & $5 \cdot 16$ & $1 \cdot 33$ & $4 \cdot 33$ & $0 \cdot 5$ & $4 \cdot 83$ & 4 & 1.5 & 5.33 & $0 \cdot 87$ & $4 \cdot 83$ & 0.83 & $5 \cdot 16$ & 6 & 1.83 & $6 \cdot 00$ & $0 \cdot 5$ & $6 \cdot 00$ & $0 \cdot 5$ & $5 \cdot 33$ \\
\hline 7 & $0 \cdot 83$ & $4 \cdot 33$ & $0 \cdot 5$ & $4 \cdot 67$ & $0 \cdot 0$ & 3.67 & 8 & $1 \cdot 50$ & $5 \cdot 50$ & $0 \cdot 0$ & $4 \cdot 00$ & $0 \cdot 0$ & $3 \cdot 50$ & 9 & $0 \cdot 33$ & $4 \cdot 83$ & 0.33 & $5 \cdot 33$ & $0 \cdot 0$ & $4 \cdot 00$ \\
\hline 10 & $1 \cdot 17$ & $5 \cdot 17$ & $0 \cdot 0$ & 5.50 & $0 \cdot 0$ & $5 \cdot 16$ & 12 & $0 \cdot 5$ & $4 \cdot 16$ & $0 \cdot 0$ & $4 \cdot 00$ & $0 \cdot 0$ & $3 \cdot 33$ & 11 & $0 \cdot 5$ & $4 \cdot 00$ & $0 \cdot 0$ & $4 \cdot 00$ & $0 \cdot 0$ & $4 \cdot 00$ \\
\hline 13 & $1 \cdot 3$ & $3 \cdot 67$ & $0 \cdot 0$ & $4 \cdot 16$ & $0 \cdot 1$ & 3.83 & 14 & 0.0 & $4 \cdot 33$ & $0 \cdot 0$ & $4 \cdot 83$ & $0 \cdot 0$ & 3.67 & 15 & $0 \cdot 5$ & $3 \cdot 17$ & $0 \cdot 0$ & $2 \cdot 33$ & $0 \cdot 0$ & $3 \cdot 00$ \\
\hline 16 & $0 \cdot 0$ & $4 \cdot 33$ & $0 \cdot 0$ & $3 \cdot 67$ & $0 \cdot 0$ & $4 \cdot 00$ & 17 & $0 \cdot 0$ & 4.16 & $0 \cdot 0$ & 4.00 & $0 \cdot 0$ & $4 \cdot 16$ & 18 & $0 \cdot 0$ & $5 \cdot 33$ & $0 \cdot 0$ & 4.67 & $0 \cdot 0$ & $4 \cdot 00$ \\
\hline 19 & $2 \cdot 0$ & $4 \cdot 00$ & $0 \cdot 0$ & 3.16 & $0 \cdot 0$ & $3 \cdot 33$ & 20 & $0 \cdot 1$ & $3 \cdot 83$ & $0 \cdot 1$ & $3 \cdot 50$ & $0 \cdot 0$ & 3.67 & 21 & 0.0 & $5 \cdot 16$ & 0.0 & $4 \cdot 83$ & $0 \cdot 0$ & $4 \cdot 33$ \\
\hline 23 & $3 \cdot 5$ & $4 \cdot 83$ & 0.0 & 4.67 & $0 \cdot 0$ & $4 \cdot 17$ & 24 & 0.0 & 4.33 & $0 \cdot 0$ & $4 \cdot 83$ & $0 \cdot 0$ & $5 \cdot 16$ & 22 & 0.0 & 5.16 & $0 \cdot 0$ & $4 \cdot 16$ & 0.0 & \\
\hline 26 & $0 \cdot 0$ & $3 \cdot 17$ & $0 \cdot 0$ & 3.67 & $0 \cdot 0$ & $0 \cdot 7$ & 25 & 0.0 & 3.67 & $0 \cdot 0$ & $3 \cdot 33$ & $0 \cdot 0$ & 3.00 & & & & & & & \\
\hline
\end{tabular}


Table 4. Complications and side-effects of drugs

\begin{tabular}{llll}
\hline Regimen & AA & BB & CC \\
\hline Complications & & & \\
$\quad$ Type I reaction & - & 1 & - \\
$\quad$ Type II reaction & 1 & 1 & 4 \\
$\quad$ Neuritis & 1 & 3 & - \\
$\quad$ Total complications & 2 & 5 & 4 \\
Side effects & & & \\
$\quad$ Headache & 1 & 2 & - \\
$\quad$ Giddiness & - & 3 & - \\
Pain in legs & 1 & 1 & 1 \\
$\quad$ Vomiting & - & 2 & 1 \\
$\quad$ Pain abdomen & 1 & 1 & 1 \\
$\quad$ Diarrhoea & - & 1 & - \\
$\quad$ Itching & - & - & 2 \\
Total cases suffered & 3 & 7 & 4 \\
Total cases in trial & 9 & 9 & 8 \\
\hline
\end{tabular}

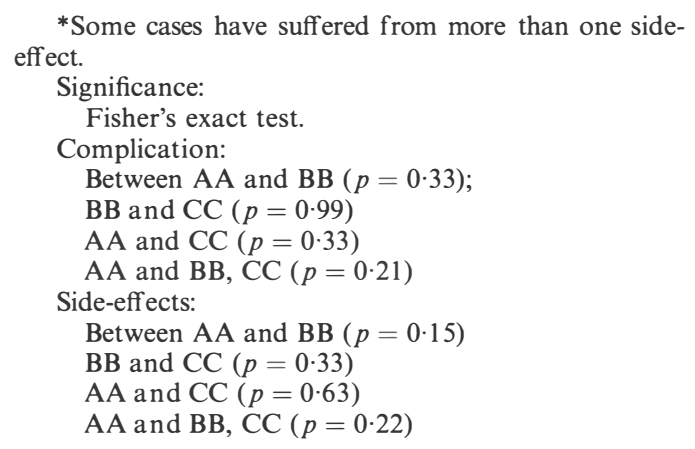

\section{COMPLICATIONS AND SIDE-EFFECTS}

Complications in the form of mild Type I and II reactions and neuritis; and side-effects to drugs such as headache, giddiness, pain in the legs, vomiting, pain in the abdomen, loose stools and itching occurred in more patients treated with $\mathrm{BB}$ and $\mathrm{CC}$ regimens, compared to AA, but the differences were not significant. Complications responded to symptomatic treatment without steroids and drug side-effects were found to be mild and these cleared with the appropriate symptomatic treatment (Table 4). All the cases taken into the trial were analysed.

\section{OTHER INVESTIGATIONS}

No significant abnormalities were noticed in haematological and biochemical investigations at intake and during the course of trial.

\section{Discussion}

Loss of infectivity in MFP has been reported on administration of 28 daily doses of $400 \mathrm{mg}$ ofloxacin in all untreated lepromatous leprosy patients. ${ }^{13}$ The results of the 
present study indirectly corroborates the above findings with $800 \mathrm{mg}$ of ofloxacin (CC), since growth positivity was noticed from biopsies treated with other regimens (BB and AA) on day 28 and beyond. But for the ambiguous MFP result of 1 patient in 'BB' regimen (case no. 8), a daily dose of $800 \mathrm{mg}$ ofloxacin does not appear to be more active against $M$. leprae than $400 \mathrm{mg}$. A killing rate of $M$. leprae of $>99 \%$ has been reported with ofloxacin in normal mice by 28 daily does. ${ }^{13}$ A lower rate of $>75 \%$ was noticed in the present study because of the very low proportion of viable organism in day 0 biopsy. The present duration of WHO recommended MDT treatment for MB patients for a minimum of 24 months was based on the fact that dapsone and clofazimine are weakly bactericidal in dealing with the possible rifampicin-resistant mutants. In view of the effectiveness of ofloxacin in making $M$. leprae non-infective in MFP by day 28 and the fast rate of kill, it should be theoretically possible to reduce the duration of therapy, if ofloxacin is added to the present WHO recommended MDT for MB leprosy. The MI appears to be useful only for monitoring the response to chemotherapy, since it was found to decline consistently with the progress of therapy. The faster clinical improvement noticed in patients who received ofloxacin-containing drug regimens has also been reported by others. ${ }^{13}$ The slow clinical response with clofazimine ${ }^{16}$ or dapsone is well known. Even when they were given together (AA) the majority $(66.7 \%)$ of patients showed no clinical improvement. Complications in the form of reactions and neuritis have not been reported by others either with ofloxacin or pefloxacin, but were noticed in the present study. ${ }^{12,13}$ However, similar drug side-effects of a mild nature were reported as noticed in the present study, and the regimens were reported to have been well tolerated as in the present study.

\section{Conclusions}

The ofloxacin containing combined drug regimens were well tolerated by lepromatous leprosy patients. The complications and side-effects were of a mild nature.

Moderate to marked clinical improvement was noticed in a short period with ofloxacincontaining regimens.

Ofloxacin if added to the currently used WHO recommended MB-MDT regimen may shorten the duration of treatment.

Ofloxacin may be considered as a suitable alternative in suspected/proven rifampicinresistant cases and where rifampicin is contraindicted.

\section{Acknowledgements}

This investigation received financial support from the UNDP/World Bank/WHO special programme for research and training in tropical diseases (TDR). We would like to express our thanks for all those in our Institute who have directly or indirectly assisted us in carrying out the study, especially Mr M. Rajendran, Technical Assistant, for his valuable assistance in mouse footpad technique, Mr E. Sathish Kumar, DPA, and Mr N. S. Rajendran, stenographer, for their secretarial assistance.

\section{References}

1 WHO, Technical Report Series No. 675, 1982: 19: 22.

2 Ji BH, Drug resistance in leprosy, a review. Lepr Rev, 1985; 56: 265-78. 
3 Petit JH, Rees RJ. Studies on sulfone resistance in leprosy. 2. Treatment with riminophenazine derivative (B663). Int J Le pr, 1966; 34: 391-7.

4 Petit JH, Rees RJW, Ridley DS. Chemotherapeutic trials in leprosy. 3. Pilot trials of a riminophenazine derivative B.663 in the treatment of lepromatous leprosy. Int $J$ Lepr, 1967; 35: 25-33.

5 Yawalkar SJ, Vischer W. Lamprene (clofazimine) in leprosy. Lepr Rev, 1979; 50: 135-44.

6 Ji BH, Chen JK, Wang CM, Xia GA. Hepatotoxicity of combined therapy with rifampicin and daily prothionamide for leprosy. Lepr Rev, 1984; 55: 283-9.

7 Pattyn SR, Janssens L, Bourland J, Saylan T, Davis EM, Grillone S, Ferraci C and The Collaborative study group for the treatment of leprosy. Hepatotoxicity of the combination of rifampicin-ethionamide in the treatment of multibacillary leprosy. Int J Lepr, 1984; 52: 1-6.

8 Jacobson RR, Hastings RC. Rifampicin-resistant leprosy. Lancet, 1976; 2: 1304-5.

9 Guelpa-Lauras CC, Grosset JH, Constant-Desportes M, Brucker G. Nine cases of rifampicin resistant leprosy. Int J Lepr, 1984; 52: 101-2.

10 Franzblau SG, White KE, Comparative in vitro activities of 20 fluoroquinolones against Mycobacterium leprae. Antimicrob Agents Chemother, 1990; 34(2): 229-31.

11 Grosset JH, Guelpa-Lauras CC, Perani EG, Beoletto C. Activity of ofloxacin against Mycobaterium leprae in the mouse. Int J Lepr, 1988; 56(2): 259-64.

12 N'Deli LN, Guelpa-Lauras CC, Perani EG, Grosset JH. Effectiveness of Pefloxacin in the treatment of lepromatous leprosy. Int J Lepr, 1990; 58(1): 12-18.

13 Grosset JH, Ji BH, Guelpa-Lauras CC, Perani EG, N'Deli LN. Clinical trial of Pefloxacin and Ofloxacin in the treatment of lepromatous leprosy. Int J Le pr, 1990; 58(2): 281-95.

14 Pocock SJ. Clinical trial-A practical approach. A Wiley Medical Publication, John Wiley \& Sons, 1984; $76-7$.

15 WHO/CDS/LEP 86.4 Laboratory techniques for leprosy. 1987; 100-4.

16 Jamet P, Traore I, Husser JA, Ji B. Short-term trial of Clofazimine in previously untreated lepromatous leprosy. Int J Lepr, 1992; 60(4): 542-8. 